\title{
EFFECTIVENESS OF SAQ AND LAQ IN ASSESSING COGNITIVE DOMAIN AMONG FIRST YEAR MBBS, BIOCHEMISTRY STUDENTS
}

\author{
Paliwal Manoj Narayan'1, Prachi Paliwal2, Darshana Jain ${ }^{3}$
}

${ }^{1}$ Associate Professor, Department of Biochemistry, Sri Aurobindo Medical College and PG Institute, Indore, Madhya Pradesh. ${ }^{2}$ Assistant Professor, Department of Biochemistry, Sri Aurobindo Medical College and PG Institute, Indore, Madhya Pradesh. ${ }^{3}$ Assistant Professor, Department of Biochemistry, Sri Aurobindo Medical College and PG Institute, Indore, Madhya Pradesh.

\section{ABSTRACT}

\section{BACKGROUND}

There are various measures used in formative assessment such as Essay Questions (EQ), Short-Answer Questions (SAQ), MultipleChoice Questions (MCQ) and Long Answer Questions (LAQ).

The aim of the present study was to find out the effectiveness of SAQ and LAQ in assessing cognitive domain among First MBBS students.

\section{MATERIALS AND METHODS}

The study was conducted in the Department of Biochemistry, SAIMS Medical College and PG Institute, Indore. Students of first MBBS were examined to assess cognitive domain by giving SAQ and LAQ of 15 marks each. Marks obtained from both types of questions were evaluated and the results were compared among 20 high and 20 low achievers.

\section{RESULTS}

Average marks obtained by high achievers in SAQ are 11.575 (77.16\%) and by low achievers are $7.5125(50.08 \%)$ and average marks obtained by high achievers in LAQ are 7.4 (49.41\%) respectively and by low achievers are 1.7625 (11.75\%) respectively. Maximum scoring was done in SAQ than LAQ by high and low achievers.

\section{CONCLUSION}

In our study, we found that SAQ and LAQ assessment methods in definite proportion are a better method for assessing the cognitive domain of undergraduate medical students.

\section{KEYWORDS}

Cognitive Domain, Long Answer Question, Short-Answer Question.

HOW TO CITE THIS ARTICLE: Narayan PM, Paliwal P, Jain D. Effectiveness of SAQ and LAQ in assessing cognitive domain among first year MBBS, biochemistry students. J. Evolution Med. Dent. Sci. 2016;5(95):6982-6984, DOI: 10. 14260/jemds/2016/1579

\section{BACKGROUND}

Educational objectives are divided into three domains according to the Bloom's taxonomy: cognitive (Knowledge), affective (Attitude) and psychomotor (Skills). ${ }^{1}$ Medical education is the art and science behind medical learning and teaching, has progressed remarkably. Teaching and learning have become more scientific and rigorous, curricula are based on sound pedagogical principles and problem based and other forms of active and self-directed learning have become the mainstream. ${ }^{2}$ Teachers have progressed from the role of problem-identifier to that of the solution-provider.

The assessment is a vital tool in the course of any curriculum. Assessment strategies are widely perceived to be the essential ingredient in the efforts to introduce new curricular approaches and modify the educational environment in academics. ${ }^{3}$ The assessment is a procedure, which determines overall learning process.

Financial or Other, Competing Interest: None.

Submission 24-10-2016, Peer Review 17-11-2016,

Acceptance 23-11-2016, Published 28-11-2016.

Corresponding Author:

Dr. Paliwal Manoj Narayan,

C/o. Sonu Saluja,

35 Golden Palace,

Near Basantpuri,

A. B. Road, Indore,

Madhya Pradesh.

E-mail: dr.manojpaliwal@yahoo.co.in

DOI: $10.14260 /$ jemds/2016/1579

\section{(c) (i) $\$$}

Today's medical education has profound impact on tomorrow's quality of health services. Therefore, any lacunae in innovation, training facilities and accountability may lead to under quality medical education. All the Medical Education Technology (MET) and medical education units have been directed towards imparting education to learner. ${ }^{4}$

Formative Assessment (FA) is a part of the developmental or ongoing teaching-learning process. The immediate feedback given in FA informs learners of their present state of learning and provides opportunity to modify learning in future. ${ }^{5}$ The most important characteristics of the evaluation process and the evaluation tool are relevance, validity, reliability, objectivity and feasibility. ${ }^{6}$ Multiple Choice Questions (MCQ), Short Answer Questions (SAQ), Modified Essay Questions (MEQ) and Large Answer Questions (LAQ) are the commonly used tools for assessing cognitive domain of undergraduate medical students.7

Among all these, SAQ carries greater objectivity and reliability and therefore range of subject areas tested is extended. Short-answer questions are open-ended questions that require students to create an answer. 8 They are commonly used in examinations to assess the basic knowledge and understanding (low cognitive levels) of a topic. ${ }^{9}$ The major advantage of LAQ is its potential ability to assess higher order cognitive functions. It encourages the students into critical thinking. 10

Scientific studies confirmed that it is the evaluation system rather than the educational objectives or curriculum or 
instructional techniques that have the most profound impact on what the students ultimately learn. ${ }^{11}$

The most important characteristics of the evaluation process and the evaluation tool are relevance, validity, reliability, objectivity and feasibility. The present study was undertaken to find out the effectiveness of SAQ and LAQ in assessing cognitive domain among students and to examine the performance of high achievers and low achievers based on SAQ and LAQ assessment.

\section{MATERIALS AND METHODS}

The study was conducted in the Department of Biochemistry, SAIMS Medical College and PG Institute, Indore, Madhya Pradesh. The study included 100 M.B.B.S students of first professional. They were given both the short answer questions and long essay questions. Maximum marks for SAQ as well as LAQ were 15 marks.

Long answer questions are descriptive, open-ended questions that may or may not be related to a biomedical or clinical problem. The expected length of answer varies significantly.

Short answer questions do not have a generic structure. Questions may require answers such as complete the sentence, supply the missing word, short descriptive or qualitative answers, diagrams with explanations, etc. The answer is usually short, from one word to a few lines. Often students may answer in bullet form. ${ }^{12}$

\section{The Pattern of SAQ Questions was based on -}

1. Match the following.

2. True or false.

3. Fill in the blanks.

4. One word answer.

5. Few line answers.

Students were informed about the topics to be assessed beforehand. Before performing the test, all questions were peer reviewed for their reliability and validity. Marks obtained from both types of questions were evaluated and the results were compared among 20 high and 20 low achievers.

\begin{tabular}{|c|c|c|}
\hline \multicolumn{3}{|l|}{ RESULTS } \\
\hline Sl. No. & SAQ Low Achievers & SAQ High Achievers \\
\hline 1 & 5 & 10.75 \\
\hline 2 & 5 & 10.75 \\
\hline 3 & 5.25 & 10.75 \\
\hline 4 & 6 & 10.75 \\
\hline 5 & 6.5 & 11 \\
\hline 6 & 6.5 & 11 \\
\hline 7 & 6.5 & 11.25 \\
\hline 8 & 7 & 11.25 \\
\hline 9 & 7 & 11.25 \\
\hline 10 & 9.25 & 11.5 \\
\hline 11 & 7.25 & 12 \\
\hline 12 & 7.25 & 12 \\
\hline 13 & 7.25 & 12 \\
\hline 14 & 9 & 12 \\
\hline 15 & 8 & 12 \\
\hline 16 & 9.25 & 12 \\
\hline 17 & 9 & 12.25 \\
\hline 18 & 9.5 & 12.5 \\
\hline 19 & 9.75 & 12.5 \\
\hline 20 & 10 & 12 \\
\hline $\begin{array}{l}\text { Average } \\
\text { Marks }\end{array}$ & 7.5125 & 11.575 \\
\hline \multicolumn{3}{|c|}{$\begin{array}{l}\text { Table 1. Marks Obtained by Low } \\
\text { Achievers and High Achievers in SAQ }\end{array}$} \\
\hline
\end{tabular}

*SAQ: Short Answer Question

Table 1 showed that average marks obtained by high achievers in SAQ are 11.575 (77.16\%) and by low achievers are 7.5125 (50.08\%), respectively.

\begin{tabular}{|c|c|c|}
\hline Sl. No. & $\begin{array}{l}\text { LAQ Low } \\
\text { Achievers }\end{array}$ & $\begin{array}{l}\text { LAQ High } \\
\text { Achievers }\end{array}$ \\
\hline 1 & 0 & 6 \\
\hline 2 & 1 & 6 \\
\hline 3 & 1 & 7 \\
\hline 4 & 1 & 7 \\
\hline 5 & 1 & 7.25 \\
\hline 6 & 1 & 6 \\
\hline 7 & 1.5 & 7.5 \\
\hline 8 & 1.5 & 8 \\
\hline 9 & 1.5 & 6.25 \\
\hline 10 & 2 & 8 \\
\hline 11 & 2 & 8.25 \\
\hline 12 & 2 & 8 \\
\hline 13 & 2 & 7 \\
\hline 14 & 2 & 7 \\
\hline 15 & 2 & 6.5 \\
\hline 16 & 2.25 & 7 \\
\hline 17 & 2.5 & 7 \\
\hline 18 & 3 & 9 \\
\hline 19 & 3 & 8 \\
\hline 20 & 3 & 11.5 \\
\hline $\begin{array}{c}\text { Average } \\
\text { Marks }\end{array}$ & 1.7625 & 7.4125 \\
\hline \multicolumn{3}{|c|}{$\begin{array}{c}\text { Table 2. Marks Obtained by Low Achievers } \\
\text { and High Achievers in LAQ }\end{array}$} \\
\hline
\end{tabular}

\section{*LAQ: Long Answer Question}

It is evident from Table 2, average marks obtained by high achievers in LAQ are $7.4(49.41 \%)$ respectively and by low achievers are $1.7625(11.75 \%)$ respectively.

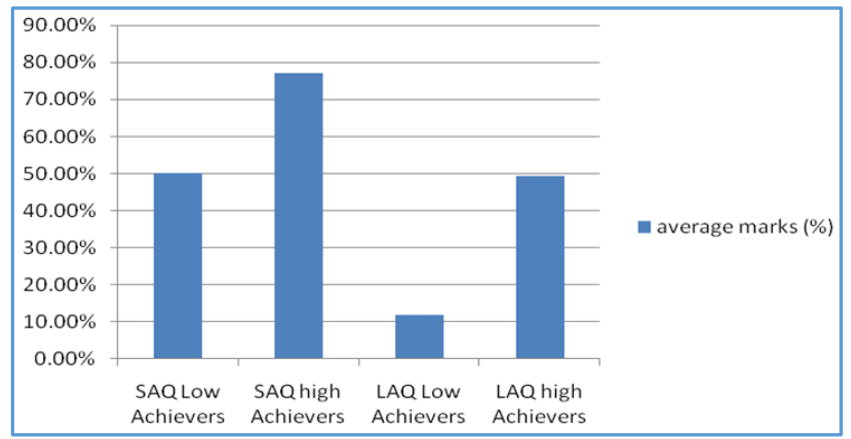

Figure 1. Average Marks in Percentage (\%) from All Groups

Figure No. 1 shows that maximum scoring was done by high achievers in SAQ followed by low achievers in SAQ and then high achievers in LAQ followed by low achievers in LAQ.

\section{DISCUSSION}

Curriculum designing, teaching learning methods and assessment are the important components of educational spiral. ${ }^{1}$

The SAQs and MCQs are an extensively used and time tested method of assessment of knowledge in national and 
international examination.

These are of different types as classified by Hubbard and Clemans (1971). Introducing a judicious mix of SAQs and MCQs along with a long answer type questions in various MBBS university exams will provide a much-needed objectivity in the assessment and would reduce the student's exposure to examiner's fallibility. ${ }^{13}$ SAQs, MCQs and LAQs are used to test cognitive domain of students, e.g. comprehension, interpret, recall, ability to apply. They form part of Written (theory) Examination. In our study, we found that high achievers as well as low achievers performed better in SAQ as compared to LAQ. This finding was in accordance to the findings of other studies. ${ }^{14,15,16}$

Bodkha P (2012) ${ }^{14}$ compared the marks obtained by high achievers and low achievers in MCQ, SAQ and Modified Essay Question (MEQ) and found that both the groups scored maximum marks in SAQ method. Also suggested that instead of using single assessment tool multiple assessment tools should be used in definite proportion to assess the cognitive domain of undergraduate medical students.

Gyata Mehta (2015) ${ }^{15}$ stated that to make any assessment fair and valid, the written tests should be strategically mixed with all types of questions. Walke YS (2014) ${ }^{13}$ recommended the suitable of incorporating both SAQs and MCQs along with long answer type questions in routine assessment of MBBS students.

Short answer questions can be used as part of a formative and summative assessment, as the structure of short answer questions are very similar to examination questions, students are more familiar with the practice and feel less anxious. A long essay question also assesses the student's ability to collate and organise information and to present their ideas succinctly and logically.

SAQ enables the student to think and came to a conclusion about the answer and it is not a chance phenomenon. It helps in rationale basis for answering the questions. In LAQ, student has to mug up the entire portion. In SAQ, something can be written to obtain marks. However, Moqattash et al (1995) ${ }^{17}$ stated that long essay type assessment is a sensitive test requiring students not only to recall facts, but also to use higher order cognitive skills such as analytical, interpretive and application skills. Thus, greater objectivity, reliability and validity were provided by using such assessment tools.

\section{CONCLUSION}

In our study, we found that SAQ and LAQ assessment methods in definite proportion are a better method for assessing the cognitive domain of undergraduate medical students. Student's approach towards learning can be significantly influenced by the method of Teaching and Evaluation. LAQs and SAQs form important components of written examination. Advantages, limitations and general guidelines should be kept in mind; also systematic approach is required while framing LAQs and SAQs.

\section{REFERENCES}

1. Bloom BS. Taxonomy of educational objectives, handbook I. The cognitive domain. New York, David McKay Co Inc 1956.
2. Editorial: assessments in medical school. Med Educ 1976;10(2):79-80.

3. Thosar N, Vagha S. Students perceptions about the effectiveness of implementing innovative teaching and assessment methods. JHSE 2015;2(1):13-9.

4. Kshirsagar N. Issues and challenges in medical education. In: Bhuiyan PS, Rege NN, Supe AN. (eds) The art of teaching medical students. Mumbai: medical education technology cell, seth GSMC and KEM Hospital 2002:3-6.

5. Jain V, Agarwal V, Biswas S. Use of formative assessment as an educational tool. J Ayub Med Coll Abbottabad 2012;24(3-4):68-70.

6. Ananthakrishnan N. Principles of evaluation. In: Sethuraman KR, Kumar S. Medical education principles and practice. $2^{\text {nd }}$ edn. Alumini association of national teacher training centre JIPMER, Pondicherry India 2000:99-104.

7. Adeniyi OS, Ogli SA, Ojabo CO, et al. The impact of various assessment parameters on medical students performance in first professional examination in physiology. Niger Med J 2013;54(5):302-5.

8. Wakeford RE, Roberts S. Short answer questions in an undergraduate qualifying examination: a study of examiner variability. Med Educ 1984;18(3):168-73.

9. Sabherwal U. Short answered questions. In: Sood R, Paul VK, Sahni P, et al. (eds) Assessments in medical education: trend and tools. New Delhi: KLWig centre for medical education and technology 1995:27-31.

10. Amin Z, Khoo HE. Basics in Medical Education. $2^{\text {nd }}$ edn. World scientific publishing Co Pte Ltd 2009.

11. Miller GE. Educational strategies for the health professions. In: developments of educational programmes for the health professionals. WHO Public health papers 1973:52.

12. Mishra A. Multiple choice questions and other methods of evaluation in anatomy: a comparative study. Journal of Evolution of Medical and Dental Sciences 2013;2(37):6788-91.

13. Walke YS, Kamat AS, Bhounsule SA, et al. A retrospective comparative study of multiple choice questions versus short answer questions as assessment tool in evaluating the performance of the students in medical pharmacology. International Journal of Basic \& Clinical Pharmacology 2014;3(6):1020-3.

14. Mehta G, Mokhasi V. Efficacy of multiple choice questions as a tool for formative assessment. International Journal of Development Research 2015;5(1):2941-4.

15. Bodhka P. Effectiveness of MCQ SAQ and MEQ in assessing cognitive domain among high and low achievers. IJRRMS 2012;2(4):25-8.

16. Dakum NK, Misauno M, Yiltok SJ, et al. Analysis of final year medical students examination in surgery. Ann Afr Med 2009;8(1):66-8.

17. Moqattash S, Harris PF, Gumaa KA, et al. Assessment of basic medical sciences in an integrated systems-based curriculum. Clin Anat 1995;8(2):139-47. 